\title{
ANALYSIS OF POLYBROMINATED BIPHENYLS BY GAS CHROMATO- GRAPHY WITH ELECTRON-CAPTURE DETECTION
}

\section{J. A. SWEETMAN*** and E. A. BOETTNER}

Department of Enviranmental and Industrial Health, University of Michigan, Ann Arbor, MI 48109 (U.S.A.)

(First received March 23rd, 1981; revised manuscript received September 7th, 1981)

\section{SUMMARY}

The structure-sensitivity relationship of polybrominated biphenyls analyzed by an electron-capture detector was investigated. The greatest variations in sensitivity with positional isomerism occurred for the least brominated isomers and for polybrominated biphenyls with bromine substituents on only one ring. The ratio of sensitivity (on a molar basis) of decabromobiphenyl to 2-bromobiphenyl was $c a$. 50, with response increasing approximately linearly with degree of bromination. Increased detector temperature resulted in improved sensitivity. The presence of oxygen in the carrier gas resulted in slightly decreased sensitivity.

\section{INTRODUCTION}

Polybrominated biphenyls (PBBs) are compounds manufactured as fire retardants for use in plastics. Industrial PBBs are produced by direct bromination of biphenyl yielding mixtlires of compounds differing both in the number of bromines atoms per molecule and by positional isomerism". In 1973 these toxic chemicals were accidentally introduced into the human food chain in Michigan $^{2-5}$. Since this incident, environmental and human contamination by PBBs has also been found near plants in New Jersey where octabromo- and decabromo-biphenyls were manufactured ${ }^{6}$.

The initial concern over the biochemical and physiological effects of PBBs was due to recognition of the structural similarities of the PBBs to the polychlorinated biphenyls (PCBs). The ability of PCBs to induce the hepatic mixed-function oxidase (MFO) enzymes has been well studied ${ }^{7}$. On a molar basis, the PBBs are ca. five times more potent than the PCBs in the induction of the MFO enzymes ${ }^{8}$.

Both PCBs $^{9}$ and $\mathrm{PBBs}^{10}$ accumulate in human adipose tissue and exhibit long half-lives. PCBs have been found to be immunosuppressive agents ${ }^{11}$. PBBs have been shown to be immunosuppresive in mice ${ }^{12}$ and in swine ${ }^{13}$. Decreased immune system function was reported in Michigan dairy farmers exposed to $\mathrm{PBB}^{14}$. However, no consistent correlation was found between the concentration of PBB in their blood plasma and the degree of immune response alteration.

* Present address: Department of Chemistry, University ô Waterloo, Waterioo, Ontario N2L 3G1, Camraxis. 
Quantification of PCB and PBB residues has been accomplished mainly by gas chronatography $(\mathrm{GC})$ with electron-capture detection ${ }^{15}$. The electron-capture detector (ECD) is utilized because of its sensitivity for halogenated compounds and its wide availability. Where the PCB or PBB pattern of congeners does not exactly match the aqailable commercial formulations, quantification is complex since the response or sensitivity of the ECD depends on the position of the halogen on the biphenyl nucleus as well as the number of halogens ${ }^{1.16}$. A model for calculating the ECD response of the 209 PCBs has been published ${ }^{17}$. No systematic study of structuresensitivity relationships for PBBs analyzed by a modern pulsed ECD has previously been reported.

The ECD responses to 22 individual $\mathrm{PBBs}$ containing $1-6$ bromine atoms per molecule were measured. In addition several isomers from FireMaster FF-1 (containing 6 or 7 bromine atoms) and Bromkal 80-9D (containing 8-10 bromine atoms) were utilized after liquid chromatographic pre-separation and microcoulometric quantification. Two ECD temperatures were examined. The effect of the addition of oxygen to the carrier gas was also investigated.

\section{EXPERIMENTAL}

\section{$P B B$ standards}

Twenty PBB isomers ( $1-6$ bromine atoms) were obtained from RFR Corporation (RI, U.S.A.). The catalogue listed the isomers as $95 \%$ pure. Three additional pentabromobiphenyls were supplied by Dr. S. Safe (University of Guelph, Ontario, Canada) FireMaster FF-1 (lot FF1312-FT) was received from the National Institute of Environmental Health Science and FireMaster FF-1 (lot FH7042) was received from the Detroit Laboratories of the U.S. Food and Drug Administration. Bromkal 80-9D was received from Dr. O. Hutzinger (University of Amsterdam, The Netherlands).

Standards were prepared by weighing milligram amounts on an August Sauter 10-mg capacity balance, and transferring to 100-ml flasks. Baker Resi-Analyzed (or comparable interference-free) hexane was used as the solvent. Volumetric dilutions were made as required. Standards were stored in glass test-tubes with PTFE-lined caps under refrigeration and were wrapped in aluminum foil to shield from light.

Gas chromatography-electron-capture detection

A Hewlett-Packard 5730A gas chromatograph with a side-mounted Linear Electron Capture Detector (constant current) was employed during this study. To minimize water and oxygen contaminants in the argon-methane (95:5) carrier gas, a Supelco carrier gas purifier at $600^{\circ} \mathrm{C}$ with a molecular sieve $5 \mathrm{~A}$ pretrap was used. Giass columns (6 ft.) packed with 3\% SE-30 on 100-120 mesh Gas-Chrom $Q$ were operated isothermally. Area measurements for this study were determined using a Hewlett-Packard 3380A integrator.

An adapter made of inert ${ }^{18}$ nickel tubing (Regis Chemical Co., IL, U.S.A.) allowed additional carrier gas flow to be added after the GC column and before the ECD. This permitted oxygen to be added after the column, thus avoiding deterioration of the GC packing. The oxygen fow-rate was limited by a porous stainless-steel flow restricter installed between the oxygen regulator and a "tee" connection to the 
gas flow. For pressure difference of $c a .30$ p.s.i., the restricter allowed a flow-rate of 1 $\mathrm{ml} / \mathrm{min}$. An increase in the standing frequency was used as an indication that oxygen was reaching the detector.

\section{High-performance liquid chromatography}

High-performance liquid chromatography (HPLC) was employed to partially purify isomers from FireMaster FF-I and Bromkal 80-9D formulations, which were then analyzed by an ECD and quantified by microcoulometric detection. The preseparation was necessary since baseline separation of the components in FF-1 was not achieved by GC. In addition; if the solutions were concentrated for analysis of the minor isomers, the major peaks $\left(2,2^{\prime}, 4,4^{\prime}, 5,5^{\prime}\right.$-hexabromobiphenyl ${ }^{19}$ in FF-I and a nonabromobiphenyl ${ }^{20}$ in Bromkal) would overload both the ECD and the microcoulometric detector. The elution order from the Partisil 5 ODS reversed-phase HPLC column employed was favorable for easy separation of isomers which gave overlapping peaks by GC. For FireMaster FF-1 a mobile phase of water-methanol (10:90) was used. For Bromkal 80-9D a mobile phase of water-ethanol (12:88) provided satisfactory separation. The UV detector wavelength was set at $225 \mathrm{~nm}$ for optimum sensitivity. Fractions of the HPLC effluent associated with peaks were collected in smali vials and the mobile phase was evaporated. Several $20-\mu 1$ injections of FF-1 and of Bromkal were made, and the corresponding fractions from each injection were pooled. The contents of the vials were then diluted with an appropriate amount of hexane and analyzed by electron-capture detection and by microcoulometric detection. The remaining $\mathrm{PBB}$ in each vial was concentrated for analysis by mass spectrometry.

\section{Gas chromatography-microcoulometric detection}

A Dohmann DE-20 halogen-specific microcoulometric GC detector adapted to a Microtek MT-220 gas chromatograph with a Texas Instruments recorder was used to quantify PBB isomers in solution. For detection, the halogen content of the GC effluent is, through oxidative pyrolysis, converted into titratable halides. If the number of bromines per molecule (from mass spectral analysis) for a given GC peak is known, the amount of the particular PBB can be determined.

\section{Mass spectrometry}

An AEI MS 30 double-beam mass spectrometer connected via a silicone membrane to a Pye Series 104 gas chromatograph was utilized for GC-mass spectrometric measurements.

\section{RESULTS AND DISCUSSION}

\section{Linearity}

The constant-current ECD was designed to give linear response over a wide range of concentrations 21 . Linear response has been questioned for strongly electronattaching compounds ${ }^{22}$. A study of detector linearity was conducted on $2,2^{\prime}, 4,4^{\prime}, 5,5^{\prime}-$ hexabromobiphenyl. This isomer was chosen because it is the major component in FireMaster FF-1 (the PBB formulation involved in the Michigan contamination incident) and because a hexabromobiphenyl was the most highly brominated, and 
therefore presumably the strongest electron-attaching, PBB isomer available in pure form. Conditions typically used for the analysis of PBBs in environmental samples were employed. Table I shows that the ECD response was linear over a concentration range of 600 , from 40 to $24,300 \mathrm{pg}$.

\section{TABLE I}

\section{LINEARITY OF DETECTOR RESPONSE TO $2,2^{\prime}, 4,4^{\prime}, 5,5^{\prime}$-HEXABROMOBIPHENI'L}

Linear regression. $r^{2}=0.998$. Conditions: column, $6 \mathrm{ft}, 3 \% \mathrm{SE}-30$ on $100-120$ Gas-Chrom Q; column temperature, $240^{\circ} \mathrm{C}$; inlet temperature, $250^{\circ} \mathrm{C}$; detector temperature, $300^{\circ} \mathrm{C}$; carrier gas, methane-argon (5:95): llow-rate, $41 \mathrm{ml} / \mathrm{min}$.

\begin{tabular}{rllll}
\hline Injexted (pg) & Injected $(\mu l)$ & $\begin{array}{l}\text { Retention } \\
\text { time }(\mathrm{min})\end{array}$ & $\begin{array}{l}\text { Peak area } \\
(\mu V \text { sec)* }\end{array}$ & $\begin{array}{l}\text { Response } \\
(\mu V \text { sec } \\
\mu g \text { sample; }\end{array}$ \\
\hline 40 & 5 & 12.5 & $2.94 \cdot 10^{4}$ & 735 \\
405 & 5 & 12.1 & $3.50 \cdot 10^{5}$ & 864 \\
4050 & 5 & 11.5 & $3.45 \cdot 10^{6}$ & 852 \\
24300 & 5 & 11.0 & $1.91 \cdot 10^{7}$ & 786 \\
\hline
\end{tabular}

* Average of two values; duplicate injections varied by less than $5 \%$.

\section{Retention times}

The range of retention times (see Tables II and III) varied from $0.8 \mathrm{~min}$ for 2bromobiphenyl with a column flow-rate of $40 \mathrm{ml} / \mathrm{min}$ to $73.5 \mathrm{~min}$ for decabromobiphenyl with a column flow-rate of $107 \mathrm{ml} / \mathrm{min}$ (total flow-rate through the detector, i.e. column flow-rate plus adapter flow-rate, was kept at $160 \mathrm{ml} / \mathrm{min})$. Substitution ortho to the biphenyl linkage $\left(2,2^{\prime}, 6\right.$ or $\left.6^{\prime}\right)$ results in the shortest retention times on the nonpolar SE-30 GC column. Para bromines (4 or $4^{\prime}$ ) cause the PBB to be most retained. Addition of bromine always increases the retention time, but positional differences are sufficient that $3,3^{\prime}, 5,5^{\prime}$-tetrabromobiphenyl has a greater retention time than $2,2^{\prime}, 4,5^{\prime}, 6$-pentabromobiphenyl.

Utilizing the retention time data shown in Table II for a column temperature of $240^{\circ} \mathrm{C}$ and a column flow-rate of $40 \mathrm{mi} / \mathrm{min}$, the following empirical equation for retention times $\left(t_{R}\right)$ based on the number of bromines in the ortho, meta, and para positions was produced:

$$
\log t_{R}(\mathrm{sec})=1.44+0.14 \sum \text { ortho-Br }+0.26 \sum \text { meta-Br }+0.29 \sum \text { para-Br }
$$

Although this equation is specific for the column and conditions used, a similar polarity column phase should result in a similar ordering of retention times. This is confirmed by the similar results reported for the phase $O V-101^{20}$ and by the fact that the non-ortho-substituted $3,3^{\prime}, 4,4^{\prime}, 5,5^{\prime}$-hexabromobiphenyl has been found to have a longer retention time than ortho-substituted hexabromobiphenyls on the $\mathrm{GC}$ phases $O V-17^{20}$ and $O V-210^{I}$.

The $2,2^{\prime}, 4,4^{\prime}, 6,6^{\prime}$-hexabromobiphenyl standard was found to contain three large peaks. The above equation was used to determine whether any of these peaks could reasonably be assigned as the $2,2^{\prime}, 4,4^{\prime}, 6,6^{\prime}$-hexabromobiphenyl peak. The pre- 
TABLE II.

\section{ECD RESPONSE TO PBBS}

Total low-rate through detector $160 \mathrm{ml} / \mathrm{min}$; flow-rate through $\mathrm{GC}$ column, $40 \mathrm{ml} / \mathrm{min}$.

\begin{tabular}{|c|c|c|c|c|c|}
\hline$P B B$ isomer & $\begin{array}{l}\text { Retention } \\
\text { rime } \\
\text { (min; ; }\end{array}$ & $\begin{array}{l}\text { Response } \\
\left(10^{-6}\right) \star \star\end{array}$ & $\begin{array}{l}\text { Relative } \\
\text { response }\end{array}$ & $\begin{array}{l}\text { Response } \\
350^{\circ} \mathrm{C} / 300^{\circ} \mathrm{C}\end{array}$ & Impurities $(\%)^{8}$ \\
\hline 2- & 0.78 & $14.9 \pm 0.5$ & 1.0 & 1.3 & $<1$ \\
\hline 3- & 0.89 & $27.7 \pm 0.6$ & 1.9 & 1.3 & $<1$ \\
\hline 4 & 0.92 & $45.8 \pm 3.1$ & 3.1 & 1.3 & $20-25$ \\
\hline $2,2^{\prime}-$ & 1.01 & $33.4 \pm 0.3$ & 2.2 & 1.5 & 4 \\
\hline $2,4-$ & 1.15 & $125.5 \pm 2.4$ & 8.4 & 1.2 & $<1$ \\
\hline 2,5 & 1.13 & $139.0 \div 0.5$ & 9.3 & 1.2 & $<1$ \\
\hline 2,6 & 1.03 & $137.4 \pm 1.8$ & 9.2 & 1.2 & 6 \\
\hline $4,4^{\prime}-$ & 1.60 & $108.7 \div 1.3$ & 7.3 & 1.2 & $<1$ \\
\hline $2,2,5-$ & 1.58 & $176.6 \pm 2.4$ & 11.9 & 1.3 & $<1$ \\
\hline 2,$3 ; 5$ & 1.98 & $177.1 \pm 4.9$ & 11.9 & 1.4 & 2 \\
\hline $2,4^{\circ}, 5$ & 2.11 & $209.8 \pm 1.0$ & 14.1 & 1.3 & $<1$ \\
\hline $2,4,6$ & 1.59 & $255.9 \pm 3.5$ & 17.2 & 1.3 & $<1$ \\
\hline 2,$2 ;, 4,5^{\prime}-$ & 2.89 & $231.1 \pm 5.1$ & 15.6 & 1.3 & 2 \\
\hline 2,$2 ;, 5,5^{\prime}$ & 2.73 & $204.9 \pm 1.8$ & 13.8 & 1.3 & 7 \\
\hline $2,2^{\prime}, 5,6^{\prime}-$ & 2.35 & $229.8 \pm 1.5$ & 15.4 & 1.3 & $<1$ \\
\hline $3,3^{\prime}, 5,5^{\prime}-$ & 4.33 & $187.4 \pm 2.3$ & 12.6 & 1.4 & 3 \\
\hline $2,2,3,4,5$ & 6.15 & $370.1 \pm 7.1$ & 24.8 & 1.3 & 1 \\
\hline $2,2,4,5,5^{\prime}$ & 5.43 & $341.9 \pm 6.5$ & 23.0 & 1.3 & 3 \\
\hline $2,2,4,5^{\prime}, 6$ & 4.14 & $295.9 \pm 6.7$ & 19.9 & 1.3 & 7 \\
\hline 2,$3 ;, 4,4 ;, 5-$ & 8.40 & $320.8 \pm 1.9$ & 21.5 & 1.4 & 4 \\
\hline $2,2^{\prime}, 4,4^{\prime}, 5,5^{\prime}-$ & 11.06 & $377.5 \pm 9.0$ & 25.3 & 1.2 & $<1$ \\
\hline $3,3^{\prime}, 4,4^{\prime}, 5,5^{\prime}-$ & 26.36 & $289.2 \pm 4.9^{38}$ & 19.4 & 1.3 & 1 \\
\hline $2.2^{\prime} .4 .4^{\prime} \cdot 6.6^{\prime}-$ & 6.20 & - & - & - & 68 \\
\hline
\end{tabular}

* Column temperature, $240^{\circ} \mathrm{C}$.

** Response $=$ area $(\mu V$ sec) $/$ nmole \pm S.D.; $n \geqslant 3$ unless noted. Slope sensitivity, $m V / m=0.30$.

* $\star$ Relative to 2-bromobiptenyl at $300^{\circ} \mathrm{C}$ detector temperature.

- Percentage of chromatographic area (exclusive of solvent) resulting from impurity peaks.

$\$ n=2$.

dicted retention time for this isomer using the above equation is $6.3 \mathrm{~min}$; a peak at $t_{R}$ 6.2 min was therefore assumed to be the actual isomer peak. Mass spectral data confirmed this peak to be a hexabromobiphenyl.

\section{Impurities}

The percentages of impurities in the PBB isomers are listed in Table II. These values are estimations made by comparing areas, assuming that the ECD response to the impurity is the same as the response to the isomer in question. Where the retention times of the impurities are greater than that of the isomer, the impurities may be overestimated since they are likely more highly brominated than the main solution component. Poor electron-capturing impurities, such as biphenyl itself, if present, would be underestimated. Mass spectrometry data on the 4bromobiphenyl solution and the 2,6-dibromobiphenyl solution indicate the impurities are a dibromobiphenyl 


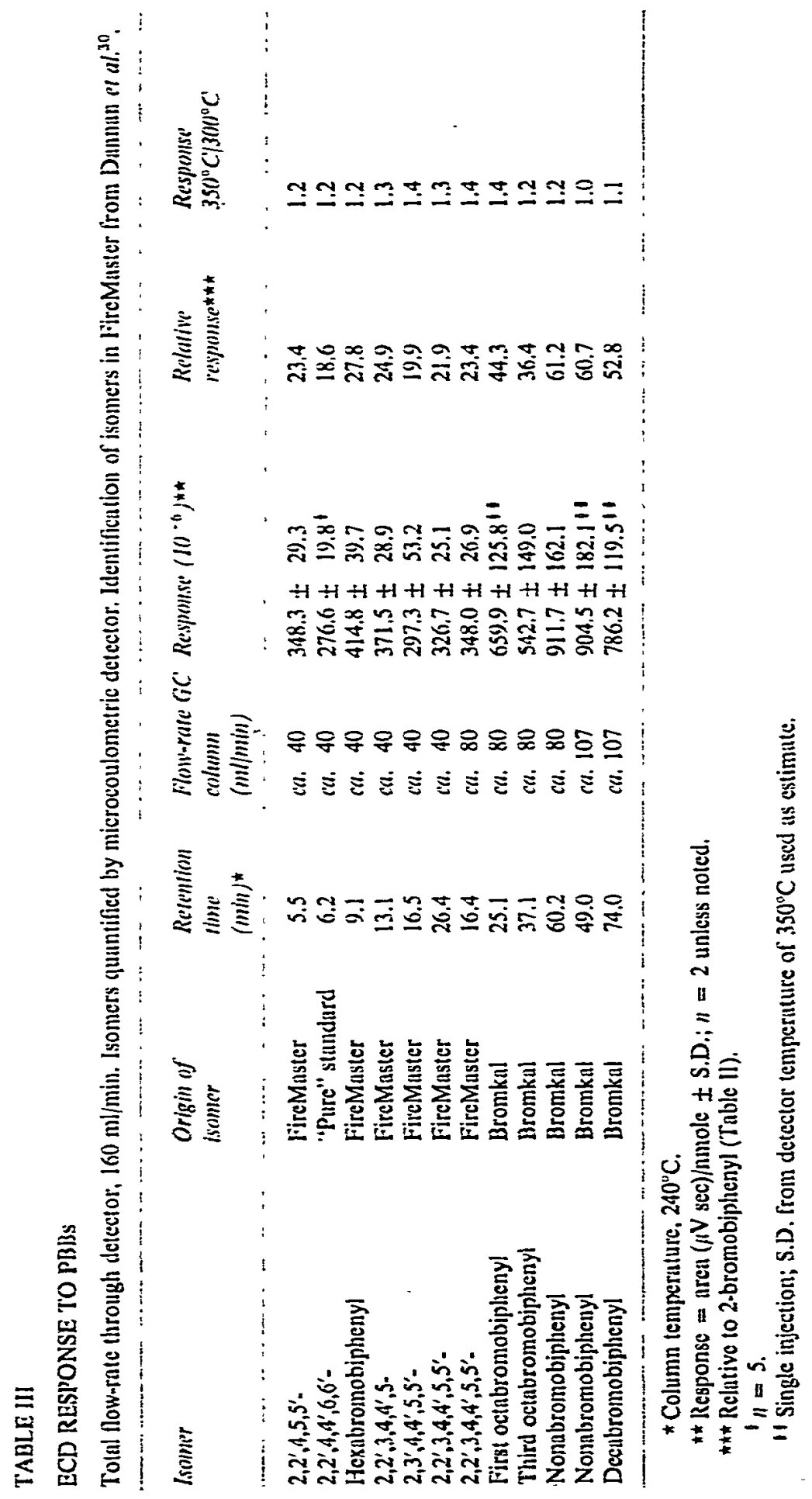


and a tribromobiphenyl, respectively. From the retention time of the dibromobiphenyl impurity it can be identified as 4,4'-dibromobiphenyl and the 4-bromobiphenyl standard can be calculated, using the response factors in Table II, to be $88 \%$ pure.

Mass spectral data for the least pure isomer, the $2,2^{\prime}, 4,4^{\prime}, 6,6^{\prime}$-hexabromobiphenyl, revealed a tribromobenzene and a tetrabromobenzene as impurities. The hexabromobiphenyl in the solution was quantified by microcoulometric detection. Samples of 2,2',4,4',6,6'-hexabromobiphenyl purchased from RFR and Aldrich prior to 1977 were reported by De Kok et al. ${ }^{20}$ to consist mainly of $2,2^{\prime}, 4,4^{\prime}, 5,5^{\prime}$-hexabromobiphenyl and to have nearly the same composition as BP-6, the formulation used to make FireMaster FF-1.

\section{ECD responses}

For comparisons of ECD response to various PBBs, high concentrations are desirable to minimize column adsorption, or possible sample decomposition effects ${ }^{23}$. The maximum frequency of pulsing was observed with an oscilloscope and the corresponding peak height on the integrator printout noted. The concentrations employed were such that this upper limit of pulsing was not reached during any peak.

The ECD responses to $23 \mathrm{PBBs}$ are listed in Table II. The fifth column shows the ratios of detector response at $350^{\circ} \mathrm{C}$ to detector response at $300^{\circ} \mathrm{C}$. The increased responses with increased detector temperature are indicative of a dissociative electron-capturing mechanism ${ }^{24}$. In Table III the ECD responses to the isomers quantified by microcoulometric detection are given. The large standard deviation (S.D.) of these values refiects the limited precision achieved by the microcoulometric quantification. In Fig. 1 the molar responses. ( $\mu \mathrm{V} \sec /$ nmole $) \cdot 10^{-6}$, are plotted versus the

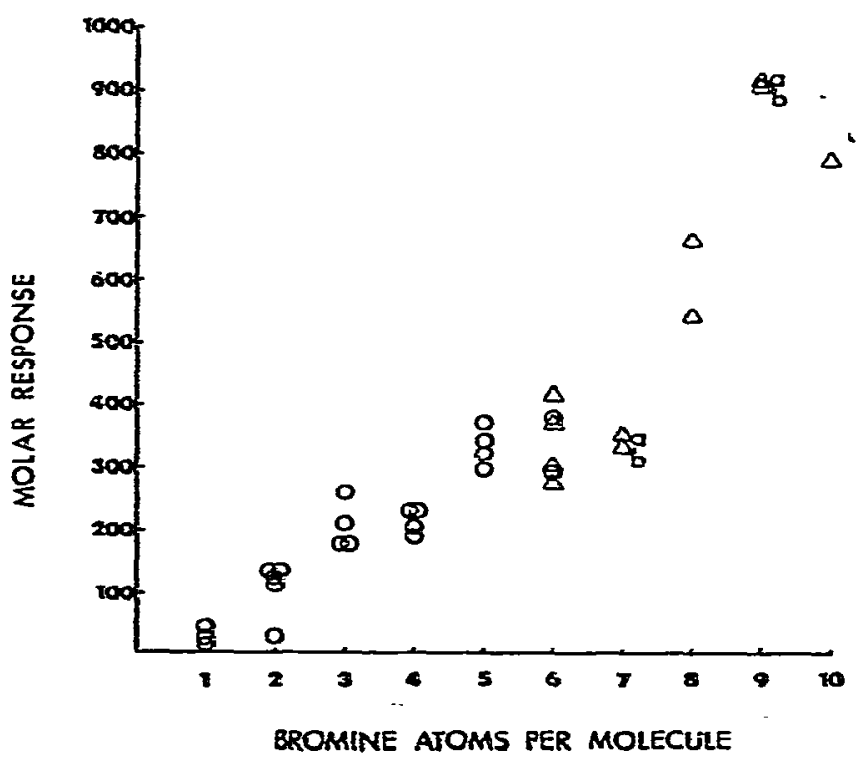

Fig. 1. ECD response to brominated biphenyls. Detector temperature, $300^{\circ} \mathrm{C}$. Molar response calculated using the area of the gas chromatographic peak; $y$-axis is molar response expressed as $(\mu \mathrm{V}$ sec(nmole) $-10^{-6} . \Delta$, solution quantified by microcoulometric detection; $\Delta_{a}$ and $\Delta_{b}$ response of a single isomer quantified from two HPLC fractions. 
number of bromine atoms per molecule. Triangles distinguish on the figure those isomers quantified by the microcoulometric detector. The apparent decrease in response of the decabromobiphenyl relative to the nonabromobiphenyl probably reflects the uncertainty in the microcoulometric quantification of these isomers rather than any real decrease in ECD response.

The greatest variation in response attributable to positional isomerism occurs for isomers with few bromine substituents, e.g. compare in Table II 2- and 4-bromobiphenyls. In addition, substitution on a single ring enhances response over splitting the same number of bromines between both rings, as is evident if one compares 2,2 and 2,6-dibromobiphenyls, or 2,4,5- and 2,4,6-tribromobiphenyls. Commercial PBB formulations, since they are produced from the bromination of biphenyl and are highly brominated mixtures, would be unlikely to contain isomers brominated on a single ring.

A linear regression of the data from Table II for molar response in $\mu \mathrm{V} \sec / \mathrm{n}$ mole gives:

molar response $=\{-19.7+64.8$ (number $\mathrm{Br} /$ molecule) $\} \cdot 10^{6} \quad r^{2}=0.87$

Only the data from Table II were used for the regression equation since the values derived based on microcoulometric quantification of the isomers have a large uncertainty. The predicted response for decabromobiphenyl using this equation is 629 , a reasonable agreement with the value found.

Since a linear regression gives a reasonable fit to the data in Fig. 1 , the analysis of $\mathrm{PBBs}$ in environmental samples can be simplified by assuming the position of the bromine on the ring can be ignored without resulting in large errors in quantification by electron-capture detection. In addition, as previously mentioned, isomers substituted on a single ring are unlikely. The insensitivity of the ECD response to positional isomerism is understandable since the molar responses, from 2-bromobiphenyl to decabromobiphenyl, increase only by a factor of ca. 50 . In terms of ECD response factors, this is not a large range. The response of $\mathrm{CCl}_{4}$, for example, is $10^{4}$ times the response of $\mathrm{CH}_{3} \mathrm{Cl}^{25}$. For $\mathrm{PCBs}$, Boe and Egaas ${ }^{17}$ found the ratio of the response of decachlorobiphenyl to 2,6-dichlorobiphenyl to be ca. 40 . In this work, for $\mathrm{PBBs}$ the corresponding ratio was $c a$. 6 . Since there is an upper limit to response, namely each collision of an electron and sample molecule resulting in an electron capture, the better electron-attaching ability of the bromine atom over the chlorine atom $^{26}$ would be expected to result in a compression of the range of sensitivities for the PBBs relative to the PCBs.

Sullivan ${ }^{27}$, calculating a collision rate for the sample molecule and an electron based on the electronic polarizability of the molecule, arrived at a theoretical upper limit of electron-capture rate constants for PCBs of varying degrees of chlorination. The highly chlorinated PCBs approached these limits, with decachlorobiphenyl at $c a$. $70 \%$ of the theoretical value. The highly electron-capturing compounds which approach the collision limit of ECD response, would also be expected to give coulometric response, i.e. one electron captured for each sample molecule, under conditions of excess electrons ${ }^{28}$. In this research, near coulometric response was found for $40 \mathrm{pg}$ of $2,2^{\prime}, 4,4^{\prime}, 5,5^{\prime}$-hexabromobiphenyl when determined as follows:

For the constant-current Hewlett-Packard 5730A ECD, the current is held at 
ca. I nA. The average current, $\bar{I}_{\mathrm{d}}$, is equal to the electrons collected per pulse times the frequency, $f$, of pulsing ${ }^{21}$ :

$$
\overline{I_{\mathrm{d}}}=\mathrm{e}^{-}-f \approx 1 \mathrm{nA}
$$

Substituting in the above equation the measured value for the standing frequency, the number of electrons collected per pulse was determined for the condition when no sample is in the detector. Conversion of the integrator output, for the peak area resulting from the injection of $40 \mathrm{pg}$ of sample, from $\mu \mathrm{V}$ sec to $\mathrm{Hz}$ sec gives the number of extra pulses needed to maintain the current at $1 \mathrm{nA}$ when the sample is in the detector. Since at this low sample concentration the change in frequency was a small percentage of the standing frequency, the change in electrons collected per pulse was also small and can be approximated by the value calculated from the standing frequency. Extra pulses were required to keep the current constant since electrons were being captured by the sampie. The electrons captured then can be calculated as:

(extra pulses) $\cdot($ electrons/pulse $)=1.9 \cdot 10^{10}$

Since $40 \mathrm{pg}$ is equivalent to $3.8-10^{10}$ molecules, the electrons captured per sample molecule is 0.5 , confirming that under conditions of excess electrons near coulometric response resulted.

\section{Addition of oxygen}

Recently, intentional addition of oxygen to a carrier gas has been used to enhance ECD response to halogenated methanes ${ }^{25}$ and other simple chlorinated molecules ${ }^{29}$. In the present study the added oxygen was not quantified, but resulted in an observed 12-fold increase in the response of $\mathrm{ClCH}_{2} \mathrm{CH}_{2} \mathrm{Cl}$ at $300^{\circ} \mathrm{C}$ detector temperature. The PBB responses decreased slightly with the addition of oxygen. The ECD response decreases ranged from $0-38 \%$ at $300^{\circ} \mathrm{C}$ detector temperature and 0 $30 \%$ at a detector temperature of $350^{\circ} \mathrm{C}$. An increased noise level when the oxygen was added, requiring a decreased slope sensitivity for the integrator, may account for the decreases. No large changes in the relative responses of one PBB to another were seen with oxygen addition to the carrier gas.

\section{CONCLUSIONS}

The ratio of sensitivity by electron-capture detection (on a molar basis) of decabromobiphenyl to 2-bromobiphenyl is ca. $\mathbf{5 0}$. Response increases approximately linearly with degree of bromination. The greatest variations in sensitivity with positional isomerism occur for the least brominated isomers and for PBBs with bromine substituents on only one ring. For the highly brominated commercial formulations, if the number of bromines per molecule for a GC peak is known either from mass spectral or retention time data, good response factors can be predicted with only a few standards by assuming a linear increase in response with increasing bromine substitution.

Increased detector temperature resulted in improved sensitivity. This study shows that for the analysis of PBBs by an ECD, the presence of oxygen impurities in 
the carrier gas will not significantly affect the absolute response of the PBB or the relative response of one isomer to another.

\section{ACKNOWLEDGEMENTS}

This research was supported in part by a research contract with the Michigan Department of $\mathrm{Heal}^{+} \mathrm{h}$. We thank Ms. Gwen Ball for her assistance with the mass spectral data.

\section{REFERENCES}

1 G. Sundstrom. O. Hutringer. S. Safe and V. Zitko. Sci Total Enitron., 6 (1976) 15.

2 L. W. Robertson and D. P. Chynoweth, Environment, 17 (1975) 25.

3 L. J. Carter, Science, 192 (1976) 240.

4 K. Kay, Environ. Res., 13 (1977) 74.

5 S. M. Getty. D. E. Rickert and A. L. Trapp, CRC Crit. Rev. Environ. Control, (1977) 309.

6 F. J. DiCarlo, J. Seifler and V. J. DeCarlo, Environ. Health Perspect., 23 (1978) 351.

7 H. Matthews. G. Fries, A. Gardner, L. Garthoff. J. Goldstein, Y. Ku and J. Moore, Environ. Health Perspect., 24 (1978) 147.

8 DHEW Suidcommittee on Health Effects of PCBs and PBBs, Environ. Health Perspect., 24 (1978) 191.

9 M. Wassermann. D. Wassermann, S. Cucos and H. J. Miller, Ann. N.Y. Acad. Sci., 320 (1979) 69.

10 M. S. Wolf, H. A. Anderson, K. D. Rosenman and I. J. Selikoff, Bull. Environ. Contom. Toxicol., 21 (1979) 775.

11 J. G. Vos and J. A. Moore, CRC Crit. Rev. Toxicol., 5 (1977) 67.

12 P. J. Fraker, Toxicol. Appl. Pharmacol., 53 (1980) 1.

13 S. K. Howard, P. R. Wermer and S. D. Sleight, Toxicol. Appl. Pharmacol., 55 (1980) 146.

I4 J. G. Beiresi, J. F. Holland, H. A. Anderson, A. S. Fischbein, W. Rom, M. S. Wolff and I. J. Selikoff, Science, 199 (1978) 1207.

5 I. Pomerantz, J. Burke, D. Firestone, J. Mckinney, J. Roach and W. Trotter, Environ. Health Perspect., 24 (1978) 133.

16 V. Zitko, O. Hutzinger and S. Safe, Bull. Environ. Contam. Toxicol., 6 (1971) 160.

E7 B. Boe and E. Egaas, J. Chromatogr., 180 (1979) 127.

18 D. C. Fenimore, J. H. Whitford, C. M. Davis and A. Zlatkis, J. Chromatogr., 140 (1977) 9.

E9 L. W. Jacobs, S. Chou and J. M. Tiedje, J. Agr. Food Chem., 24 (1976) 1198.

20 J. J. de Kok. A. de Kok, U. A. Th. Brinkman and R. M. Kok, J. Chromatogr., 142 (1977) 367.

21 R. J. Maggs, P. L. Joynes, A. I. Davies and I. E. Lovelock, Aral. Chem., 43 (1971) 1965.

22 J. E. Lovelock and A. J. Watson, J. Chromatogr., 158 (1978) 123.

23 P. L. Patterson. J. Chromatogr., 134 (1977) 25.

24 J. E. Lovelock, Anal. Chem.. 35 (1963) 474.

is E. P. Grimsrud and D. A. Miller, Anal. Chem., 50 (1978) 1141.

26 E. D. Pellizari, J. Chromalogr, 98 (1974) 323.

27 J. J. Sullivan, J. Chromazogr., 87 (1973) 9.

28 E. P. Grimsrud and S. H. Kin, Anal. Chem., 51 (1979) 537.

29 D. A. Miller and E. P. Grinsred, Anal. Chem., 51 (1979) 851.

30 G. A. Dannan, R. W. Moore and S. D. Aust, Environt. Health Perspect, 23 (1978) 51. 